NBER WORKING PAPER SERIES

\title{
OLIGOPOLY DEREGULATION AND THE TAXATION OF COMMODITIES
}

\author{
Gilbert E. Metcalf \\ George Norman \\ Working Paper 9415 \\ http://www.nber.org/papers/w9415
}

\author{
NATIONAL BUREAU OF ECONOMIC RESEARCH \\ 1050 Massachusetts Avenue \\ Cambridge, MA 02138 \\ December 2002
}

The first author acknowledges support from the M.I.T. Joint Program on the Science and Policy of Global Change and a grant from the National Science Foundation (SBR-9811324) through the National Bureau of Economic Research. The views expressed herein are those of the authors and not necessarily those of the National Bureau of Economic Research.

(C) 2002 by Gilbert E. Metcalf and George Norman. All rights reserved. Short sections of text not to exceed two paragraphs, may be quoted without explicit permission provided that full credit including, (C) notice, is given to the source. 
Oligopoly Deregulation and the Taxation of Commodities

Gilbert E. Metcalf and George Norman

NBER Working Paper No. 9415

December 2002

JEL No. D43, H20, H21

\section{$\underline{\text { ABSTRACT }}$}

We examine the interplay between market structure and the form that commodity taxation should take in a world in which firms produce differentiated products and so are able to exert some degree of market power. Our analysis takes explicit account of two important recent developments that carry significant implications for market structure and so for the appropriate design and effectiveness of commodity taxation: market deregulation and technological change. In the presence of price discrimination, we find that tax policy loses much of its effectiveness at serving as a substitute for direct regulation. Moreover, in cases where taxes can influence market structure, subsides rather than taxes may be required to achieve optimum market structure.

Gilbert E. Metcalf

Department of Economics

Tufts University

Medford, MA 02155

and NBER

gilbert.metcalf@tufts.edu
George Norman

Department of Economics

Tufts University

Medford, MA 02155

george.norman@tufts.edu 


\section{Introduction}

It is well accepted that the appropriate design of commodity taxes is affected by market structure. It is equally well recognized that commodity taxes can serve as regulatory instruments to achieve desired market structure outcomes in cases where firms produce differentiated products and so are able to exert some degree of market power. This latter idea was first explicitly analyzed by Kay and Keen (1983) who showed that in differentiated product markets ad valorem taxes can be used to achieve desired product variety while specific taxes are used to set price optimally. Even if there were no need for distorting taxes for revenue raising purposes due to the existence of lump sum taxation, it still might be desirable to levy an ad valorem tax to alter the equilibrium number of firms in the market. In other words, the ad valorem tax could be welfare enhancing over some range.

The specific contribution of this paper is to extend the Kay and Keen study to introduce two elements that recent analysis of spatial and, more generally, differentiated product markets have shown to be important in determining market structure. First, we know from the work, for example, of Eaton and Wooders (1985) and Norman and Thisse (1996), Norman and Thisse (1999), that equilibrium market structure is affected by the ability of incumbents to commit to their location, or product design choices: what Norman and Thisse (1996) refer to as the degree of spatial contestability. Second, the same analyses indicate that market structure is affected by the pricing policies that firms adopt and, in particular, by whether firms price discriminate or not. There is the clear implication, which we investigate in this paper, that if spatial contestability and firms' choices of pricing policy determine equilibrium market structure in the absence of 
commodity taxes, they should also affect the design of commodity taxes that are intended to achieve social welfare objectives.

Our analysis is relevant and timely for at least two reasons. First, the last two decades have seen a significant relaxation in regulatory controls, with firms being allowed much more latitude in their choice of pricing policies. It should come as little surprise, therefore, to see the extensive application of discriminatory prices. Second, technological change over the same two decades has seen the increasingly wide adoption of flexible manufacturing systems, defined as "a production unit capable of producing a range of discrete products with a minimum of manual intervention" (U.S. Office of Technology Assessment (1984), p. 60). These systems allow firms to switch product specifications easily, with the result that firms adopting this type of technology can customize their products to the specific requirements of their buyers at little or no cost penalty. Developments in e-commerce have further extended the ability of firms to customize or "version" the services and products offered to customers based upon information gathered about each customer's preferences.

"What this means in practice is that rather than display the same set of pages to every visitor, a Web site would present different information to each customer based on the person's data profile." (Stellin (2000))

What this and the more general use of flexible manufacturing also mean is that not only do we get our very own customized products or personalized Web pages; we often also get our very own customized or personalized prices since firms find themselves unable to commit to non-discriminatory prices.

In our analysis below, we find that the differences in optimal commodity taxes across different regimes, defined by spatial contestability, technology or pricing policy, in some cases is merely one of degree. In other cases, however, it emerges that the 
difference is one of sign - taxes should be replaced by subsidies. In yet other cases we find a dramatic contrast with the Kay and Keen results in that commodity taxes lose all leverage in their ability to affect market structure. This does not mean, however, that the authorities face a chaotic environment in designing commodity taxes. We show that there are potentially observable characteristics that can be used to distinguish between the different regimes and so can be used to guide policy.

The rest of the paper is structured as follows. In the next section we outline the basic model on which our analysis is based. In the next two sections we identify the impact of commodity taxes on market structure, in section 3 when firms do not price discriminate and in section 4 in the presence of price discrimination. Our main conclusions are summarized in the final section.

\section{The Model}

We base our analysis on the Salop (1979) model that has become standard in the literature on horizontal product differentiation. A particular virtue of this model is that it explicitly allows us to identify the equilibrium number of firms and so to ascertain the connection between the regulatory and technological regime, market structure and the impact - and so optimal design - of commodity taxes.

Our market is represented as a one-dimensional attribute space with support $[0, L]$ which, to avoid end-point problems, we assume to be circular: we normalize $L=1$ without loss of generality. Firms that enter this market are assumed to offer products that are identical in all characteristics other than their locations in the attribute space. They may employ one of two technologies: a designated technology or a flexible technology. ${ }^{1}$

\footnotetext{
$1 \quad$ We do not model firms' choice of technologies but rather assume that either they all employ the designated technology or they all employ the flexible technology.
} 
When firms employ the designated technology they each produce a single good with a defined characteristic that cannot be customized, so that the "location" of firm $i$ is the characteristic $x_{i} \in[0,1]$ that this firm offers. By contrast, with the flexible technology the producer starts with a 'basic product' and customizes or personalizes it to the precise specifications of particular consumers.

"This means that the firm now produces a band of horizontally differentiated products centered upon its basic product instead of a single product." (Norman and Thisse (1996), p. 79) ${ }^{2}$

In other words, with flexible manufacturing the "location" of firm $i$ is the attribute of the basic product $x_{i} \in[0,1]$ on which the range of customized products offered by firm $i$ is centered.

Production costs for firms that enter the market are assumed to be identical and to exhibit economies of scale. The production cost function for firm $i$ is

$$
C_{i}(Q)=f+c \cdot Q
$$

where $c$ are (constant) marginal costs and $f$ are fixed costs. ${ }^{3}$ If the firms operate the flexible technology, they also incur customization costs. The cost of customizing basic product $x_{i}$ to attribute $x$ is assumed to be

$$
c_{i}(x)=r\left|x-x_{i}\right|
$$

Firms face an ad valorem tax rate $\tau_{v}$ and a unit or specific tax rate $\tau_{s}$.

Consumers are distributed over this space at density $D$ which, without loss of generality, we can normalize to $D=1$. Consumer $j$ 's "address" is defined as $x_{j} \in[0,1]$, where $x_{j}$ denotes this consumer's most preferred product attribute. Each consumer is

\footnotetext{
2 See also Eaton and Schmitt (1994) for a discussion of this model as a model of flexible manufacturing.

3 We do not compare designated and flexible equilibria with each other and so do not distinguish their fixed costs.
} 
assumed to buy exactly one unit of the product that offers her the greatest utility. The indirect utility that consumer $j$ gets from buying a product with attribute $x$ at price $p(x)$ is

$$
U_{j}(x, p(x))=V-p(x)-t\left|x-x_{j}\right|
$$

where $V$ is the consumer's reservation price. The parameter $t$ can be given one of two familiar interpretations. If we consider this to be a pure spatial model $t$ is unit transport cost, while if we think of this as a model of horizontal product differentiation, $t$ is the valuation consumers place on the utility they lose from having to consume other than their ideal product. We assume that $V$ is sufficiently large that the market is covered in each of the equilibria we consider below.

The flexible manufacturing technology has two essential characteristics. First $0 \leq$ $r \leq t$ and secondly, each consumer obtains the same utility from basic product $x_{i}$ customized to attribute $x$ as from a basic product $x$ if they are offered at the same price. ${ }^{4}$

Firms in this market compete in a two-stage game. In the first stage they (simultaneously) decide whether to enter and the locations, or attributes of their (basic) products. In the second stage they compete in prices à la Bertrand. We confine our attention to two, exogenously determined, pricing policies. With non-discriminatory pricing each firm sets a (mill) price $m_{i}$. The full price that a consumer with most preferred product attribute $x$ pays to consume firm $i$ 's product is then $m_{i}+t\left|x-x_{i}\right|$. With discriminatory pricing the only restriction imposed on firm $i$ 's price to any consumer location is that the firm never prices below marginal cost, including commodity taxes. In order to keep the analysis tractable we confine our attention throughout to symmetric locations of the entrant firms. ${ }^{5}$ We still need to identify, however, what is 
meant by equilibrium to the entry subgame. Entry takes place to the point where no additional entrant expects to break even but this leaves a potentially wide range of potential equilibria determined by the costs that incumbent firms incur in re-locating or, in the product differentiation interpretation, re-anchoring their (basic) products. We concentrate throughout on two polar cases ${ }^{6}$

(i) spatial contestability (SC) in which re-anchoring costs are zero; and spatial non-contestability $(S N C)$ in which re-anchoring costs are prohibitive.

With SC the only candidate equilibrium is the maximum packing configuration in which all incumbent firms just break even. With SNC the candidate equilibria range from this maximum packing equilibrium to the minimum packing equilibrium in which a sophisticated entrant just fails to break even given the (symmetric) locations of the incumbents. In this context a sophisticated entrant is an entrant that can "foresee the price equilibrium that would prevail if they were to enter" ((Eaton and Wooders (1985)), p. 283). We confine our attention in the SNC case to the minimum packing equilibrium. In the analyses that follow, we take as our benchmark the equilibrium number of products that maximizes social welfare. Given our specification (3) of the consumer utility function, the socially optimal degree of product variety is the number of (basic) products $N^{0}$ that minimizes total costs

$$
T C(N)=N . f+2 N \int_{0}^{1 / 2 N} h \cdot s d s=N . f+\frac{h}{4 N}
$$

which gives

\footnotetext{
$4 \quad$ The implicit assumption with the designated technology is that, while customization might be possible, it can be implemented only at a "distance" cost $r_{d}>t$ and so will be rejected by consumers. This is actually not particularly restrictive in that it can be shown that a symmetric configuration of products is a location equilibrium in this type of model (see, for example, Novshek (1980), Kats (1995)). $6 \quad$ See Norman and Thisse (1996), (1999).
} 


$$
N^{0}=\frac{1}{2} \sqrt{\frac{h}{f}}
$$

where $h=t$ with the designated technology and $r$ with the flexible technology.

\section{Tax Policy in the Absence of Price Discrimination}

In this section, we consider whether tax policy can be used to achieve optimal market structure to maximize social welfare when firms are unable to price discriminate. We focus primarily on markets with designated technologies. While we briefly consider tax policy in the presence of flexible technologies, we argue that firms are likely to price discriminate when they employ such technologies because, in the absence of regulations to the contrary, flexible manufacturing undermines the ability of firms to make credible commitments not to price discriminate. Since the firm now has the ability to offer a wide range of product variants it can, subject only to arbitrage constraints, price these variants individually. Competition between firms for individual consumers can then be expected to undermine any attempt to maintain a pricing policy with the inflexible characteristics of non-discriminatory (mill) pricing. Simply put, competition is likely to become Bertrand-at-every-point.

When firms employ designated technologies and re-anchoring is costless, the determination of the price equilibrium is as described in Kay and Keen (1983). After reviewing this equilibrium, we consider the case where re-anchoring is ruled out by high costs. Assume that there are $N$ active firms uniformly distributed over the market. Consider firm $i$ and assume that all other firms have set the mill price $m$. Then the consumer located at $x$ who is indifferent between buying from firm $i$ and the nearest neighbor to firm $i$ is characterized by 


$$
m_{i}+t x=m+t\left(\frac{1}{N}-x\right) \Rightarrow x=\frac{1}{2 N}+\frac{m-m_{i}}{2 t}
$$

Demand to firm $i$ is $2 x$ or

$$
D\left(m_{i}, m\right)=\frac{1}{N}+\frac{m-m_{i}}{t}
$$

and profit to firm $i$ is

$$
\pi_{i}=\left(\left(1-\tau_{v}\right) m_{i}-c-\tau_{s}\right) D\left(m, m_{i}\right)-f
$$

Taking the derivative with respect to $m_{i}$, setting this to zero and solving for $m_{i}$ with the symmetry assumption that in equilibrium $m=m_{i}$ gives the equilibrium price

$$
m_{i}=\frac{t}{N}+\frac{c+\tau_{s}}{1-\tau_{v}}
$$

The equilibrium number of firms is then determined by the degree of spatial contestability in the market.

Spatial Contestability (SC)

When the market is SC the equilibrium condition is, as in Kay and Keen (1983), that the entrant firms just break even. Substituting (9) into (8) with $m=m_{i}$ and simplifying gives the equilibrium condition on the degree of product variety

$$
\pi_{i}=\frac{\left(1-\tau_{v}\right) t}{N^{2}}-f=0 \Rightarrow N^{S C}\left(t, \tau_{v}, \tau_{s}\right)=\sqrt{\frac{\left(1-\tau_{v}\right) t}{f}}
$$

Substituting into (9) gives the equilibrium producer price

$$
\left(1-\tau_{v}\right) m^{*}=\frac{\left(1-\tau_{v}\right) t}{N^{S C}\left(t, \tau_{v}, \tau_{s}\right)}+c+\tau_{s}=\sqrt{\frac{f . t}{\left(1-\tau_{v}\right)}}+c+\tau_{s}
$$


It follows that unit taxes are fully passed forward in the sense of the producer price rising by the amount of the tax. ${ }^{7}$ Ad valorem tax incidence can be decomposed into two components: a direct effect and an indirect effect through the change in the equilibrium number of firms. Fixing $N$,

$$
\left.\left.\frac{\partial \widetilde{m}}{\partial \tau_{v}}\right|_{N} \equiv \frac{\partial\left(1-\tau_{v}\right) m}{\partial \tau_{v}}\right|_{N}=-\frac{t}{N}
$$

The complete incidence is given by

$$
\frac{\partial \widetilde{m}}{\partial \tau_{v}}=-\frac{1}{2} \sqrt{\frac{f . t}{1-\tau_{v}}}=-\frac{t}{2 N^{S C}\left(t, \tau_{v}, \tau_{s}\right)},
$$

half the incidence in the case where $N$ is fixed. In other words, firm exit contributes to half the incidence being shifted forward to consumers. Firms exit because an increase in ad valorem taxation is equivalent (from the firm's point of view) to an increase in fixed costs relative to revenue (see Kay and Keen for details).

Since the specific tax is passed on fully as an increase in prices, it follows - as can be seen from (10), that the equilibrium degree of product variety is a function solely of the ad valorem tax rate. Comparing (5) and (10) indicates that an ad valorem tax rate of $75 \%$ is needed to give the socially optimal number of firms.

\section{Spatial Non-Contestability (SNC)}

When the market is SNC the relevant equilibrium condition is that an entrant just fails to break even given that the incumbents do not relocate in response to entry (because re-anchoring costs are prohibitively high) but are expected by the entrant to change their

\footnotetext{
$7 \quad$ From equation (11), the consumer price rises by more than the unit tax in the presence of an ad valorem tax. The increase in price by the firm to cover the unit tax must also cover an increase in ad valorem tax collections. It is not the case, however, that the unit tax is more than 100 percent passed forward.
} 
prices optimally in response to entry. We must first, therefore, identify the Nash equilibrium prices that the entrant expects to prevail post-entry.

It is a familiar result that an entrant should locate midway between some pair of incumbents. So suppose that the entrant, denoted 0, locates midway between two incumbents, denoted -1 and 1 . The incumbents will change their prices in response to entry and this price change will affect their nearest neighbors, 2 and -2 who can be expected to change their prices, affecting their neighbors 3 and -3 and so on. A chain reaction is set up in the post-entry mill prices of the incumbent firms.

Suppose that there are $N$ firms pre-entry. Then we have the following: ${ }^{8}$

Theorem 1: The post-entry mill prices charged by the entrant $\left(m_{0}\right)$ and the incumbent firms $\left(m_{i}, i= \pm 1, \pm 2, \ldots\right)$ are:

$$
\begin{aligned}
& m_{0}\left(N, \tau_{s}, \tau_{v}\right)=\frac{c+\tau_{s}}{1-\tau_{v}}+\frac{3(1+\sqrt{3})}{3+2 \sqrt{3}} \frac{t}{2 N} \\
& m_{1}\left(N, \tau_{s}, \tau_{v}\right)=m_{-1}\left(N, \tau_{s}, \tau_{v}\right)=\frac{c+\tau_{s}}{1-\tau_{v}}+\frac{3+4 \sqrt{3}}{3+2 \sqrt{3}} \frac{t}{2 N} \\
& m_{2}\left(N, \tau_{s}, \tau_{v}\right)=m_{-2}\left(N, \tau_{s}, \tau_{v}\right)=\frac{c+\tau_{s}}{1-\tau_{v}}+\frac{7 \sqrt{3}}{3+2 \sqrt{3}} \frac{t}{2 N} \\
& m_{i}\left(N, \tau_{s}, \tau_{v}\right)=\frac{c+\tau_{s}}{1-\tau_{v}}+\left(2-\frac{3(2-\sqrt{3})^{i \mid}}{3+2 \sqrt{3}}\right) \frac{t}{2 N}(i=3,-3 ; 4,-4 ; \ldots)
\end{aligned}
$$

Using the prices from Theorem 1 to calculate the profits of the entrant and setting these to zero gives the equilibrium number degree of product variety with SNC

$$
N_{n d}^{S N C}\left(t, \tau_{v}, \tau_{s}\right)=\sqrt{\frac{3 t\left(1-\tau_{v}\right)}{2(2+\sqrt{3}) f}}
$$

The direct and complete incidences of commodity taxes are as for the SC case.

\footnotetext{
$8 \quad$ The proof follows Eaton and Wooders (1985) and can be obtained from the authors on request. See also Norman and Thisse (1996).
} 
Comparison with (10) indicates, as we would expect, that SNC leads to lower equilibrium product variety. This market environment does not, however, provide qualitatively different results from the Kay and Keen analysis. Where the optimal tax is 75 percent in the latter case, the optimal tax now is 37.8 percent. Ad valorem taxes are overshifted in both cases with the overshifting arising from firm exit in response to the ad valorem tax.

Recall that the equilibrium price is given by equation (9) in either the contestable or non-contestable market. Non-contestability affects the equilibrium number of firms and allows for the possibility of economic rents. From equations (8), (9), and (14), we can calculate rents per firm as

$$
\pi_{i}=\frac{1+2 \sqrt{3}}{3} f
$$

and aggregate profits are

$$
\Pi=\frac{(1+2 \sqrt{3}) \sqrt{\left(1-\tau_{V}\right) t f}}{\sqrt{6(2+\sqrt{3})}}
$$

In addition to serving as an instrument for achieving optimal product diversity, the ad valorem tax serves to appropriate some of the economic rents earned in non-contestable markets. With an optimal tax rate of 37.8 percent, aggregate economic rents are reduced by 21.1 percent.

We argued at the beginning of this section that firms are unlikely to be able to commit not to price discriminate when they employ flexible manufacturing systems. For completeness, however, we report results for the case where such firms can commit to non-discriminatory prices. ${ }^{9}$ The difference between this case and those analyzed above

\footnotetext{
$9 \quad$ Details can be obtained from the authors on request.
} 
is that "transport" costs are now customization costs and so are part of the tax base. Whether the market is SC or SNC there is excessive product variety in the absence of commodity taxes which can be corrected by a positive ad valorem tax: of $100 \%$ with spatial contestability and $58.2 \%$ with spatial non-contestability.

Table 1 below summarizes our results when firms can commit not to price discriminate. In all cases the equilibrium number of firms exceeds the socially optimal number of firms. Ad valorem taxes, therefore, have the capability of reducing excess product variety and achieving the social optimum. The optimizing tax rate varies from 37.8 to 100 percent depending on technology and re-anchoring costs. The qualitative result, however, is quite robust: ad valorem taxes can be used to reduce excessive product variety. We next turn to the case where firms price discriminate.

\begin{tabular}{|c|c|c|c|}
\hline \multicolumn{5}{|c|}{ Table 1. Product Variety and Optimal Ad Valorem Tax Rates: } \\
No Price Discrimination \\
\hline \multirow{2}{*}{ Technology } & Contestability & $\mathbf{N}^{*}-\mathbf{N}^{\mathbf{0}}$ & $\tau_{v}^{*}$ \\
\hline \multirow{2}{*}{ Designated } & SC & + & $75.0 \%$ \\
\cline { 2 - 4 } & SNC & + & $37.8 \%$ \\
\hline \multirow{2}{*}{ Flexible } & SC & + & $100.0 \%$ \\
\cline { 2 - 4 } & SNC & + & $58.2 \%$ \\
\hline
\end{tabular}

\section{Tax Policy With Price Discrimination}

As we pointed out in the Introduction, a trend towards weaker enforcement of regulations on firms' pricing policies has occurred both in the United States and Europe. In this section, we consider how the ability of tax policy to affect market structure is altered in the presence of price discrimination.

\subsection{Designated Technology}

We begin by assuming that the entrant firms adopt the designated technology but choose discriminatory prices. This changes the price equilibrium. The price charged by 
firm $i$ to each consumer is such that the utility for each consumer that purchases from firm $i$ is exactly what they would achieve if they bought at cost from the next most preferred competitor. If a consumer is located $z$ units to the right of firm $i$, then the pricing rule is given by:

$$
p_{i}(z)+t . z=\frac{c+\tau_{s}}{1-\tau_{v}}+t\left(\frac{1}{N}-z\right) \quad z \in\left[0, \frac{1}{2 N}\right]
$$

The marginal cost on the RHS of equation (17) must be grossed up by the tax to account for the fact that the competitor must pay taxes on its sales to a consumer. Since this is a model of product differentiation, $t$ measures utility loss and is not included in the tax base.

A similar (symmetric) equation holds for consumers to the left of the firm. It follows that the price schedule that firm $i$ applies is

$$
p_{i}(z)=\frac{c+\tau_{s}}{1-\tau_{v}}+\frac{t}{N}-2 t . z
$$

Profit to firm $i$ is, therefore

$$
\pi_{i}=2 \int_{0}^{1 / 2 N}\left(\left(1-\tau_{v}\right) p_{i}(z)-c-\tau_{s}\right) d z-f=\frac{\left(1-\tau_{v}\right) t}{2 N^{2}}-f
$$

\section{Spatial Contestability}

Entry occurs until profits go to zero. Thus, in equilibrium,

$$
N_{d}^{S C}\left(t, \tau_{v}, \tau_{s}\right)=\sqrt{\frac{\left(1-t_{v}\right) t}{2 f}}
$$

and the equilibrium consumer price is

$$
p_{i}(z)=\frac{c+\tau_{s}}{1-\tau_{v}}+\sqrt{\frac{2 t . f}{1-\tau_{v}}}-2 t . z \quad z \in\left[0, \frac{1}{2 N}\right]
$$


As in the no-price discrimination case, equation (18) indicates that with a given number of firms any taxes are fully shifted to the consumer. Once the impact of taxes on market structure is taken into account, equation (21) indicates that the excise tax is fully forward shifted while the ad valorem tax is overshifted. Increasing $\tau_{v}$ has the effect of raising fixed costs and so driving out firms. Comparison with (10) indicates, however, that as in Kay and Keen, there is an excessive number of firms in the absence of commodity taxes, a feature that is typical of spatially contestable markets. The optimal ad valorem tax rate can get us to the optimum, the optimal tax rate being $50 \%$ in this case. Spatial Non-Contestability

With spatial non-contestability and price discrimination, the price equilibrium for a sophisticated entrant is straightforward: equation (18) applies to the entrant as well as to the incumbents. In order to identify the zero-profit condition for an entrant, denote the market area obtained by an incumbent firm, given that there are $N$ firms in the market, as $M=1 / N$. Putting this into equation (19) we have that the profit of a firm with market area $M$ is

$$
\pi_{i}(M)=\frac{\left(1-\tau_{v}\right) t M^{2}}{2}-f
$$

Now consider an entrant. This firm will enter mid-way between two incumbents, charge prices characterized by the equilibrium condition (18) and so will capture a market of area $M / 2$. As a result, the entrant's profit is

$$
\pi_{i}\left(\frac{M}{2}\right)=\frac{\left(1-\tau_{v}\right) t M^{2}}{8}-f=\frac{\left(1-\tau_{v}\right) t}{8 N^{2}}-f
$$

This means that the equilibrium number of firms is 


$$
N_{d}^{S N C}\left(t, \tau_{v}, \tau_{s}\right)=\sqrt{\frac{\left(1-\tau_{v}\right) t}{8 f}}
$$

Ad valorem taxes continue to reduce product variety. However, the intense price competition that an entrant expects to face together with the product specification commitment that incumbents are able to make because of the prohibitive re-anchoring costs means that, even in the absence of commodity taxes there is too little product variety. Since an increase in the ad valorem tax rate decreases equilibrium product variety, we now find that the optimal tax rate needed to generate the socially optimal product variety is actually a subsidy of $100 \%$. Incumbent firms earn economic rents per firm of

$$
\pi_{i}=3 f
$$

and aggregate profits equal

$$
\Pi=3 \sqrt{\frac{\left(1-\tau_{v}\right) t f}{8}}
$$

In contrast to the environment in which price discrimination is prohibited, the use of a tax to achieve the optimal amount of product diversity will increase economic rents, in this model by 41.5 percent.

\subsection{Flexible Technology}

Now consider situations in which firms adopt flexible technologies. Recall that this means that the firms can customize their products to the precise requirements of their customers: in a purely spatial context it is equivalent to the firm controlling and potentially charging for delivery of the product to its consumers.

We need first to identify the price equilibrium that will result. Consider a consumer whose most preferred product attribute is between firm $i$ and $i+1$ "distance" $z$ 
from firm $i$ such that this consumer is located nearer to firm $i$ than firm $i+1$. Competition between firms $i$ and $i+1$ drives the price down to the point at which firm $i+1$ cannot break even. If firm $i+1$ quotes a price $p(z)$ to this consumer then, given an ad valorem tax rate of $\tau_{v}$ and a specific tax of $\tau_{s}$, firm $i+1$ receives post-tax revenues of $p(z)\left(1-\tau_{v}\right)-\tau_{s}$ and this must be no less than costs $c+r(1 / N-z)$. The Nash equilibrium price that firm $i$ charges to consumer $z$ with Bertrand competition is the minimum price firm $i+1$ can quote, giving firm $i$ 's equilibrium price schedule for consumers between firms $i$ and $i+1$ as:

$$
p_{i}(z)=\frac{c+\tau_{s}+r\left(\frac{1}{N}-z\right)}{1-\tau_{v}} \quad z \in\left[0, \frac{1}{2 N}\right]
$$

Equation (27) differs from equation (18) in that the cost of customization (r) is now included in the tax base whereas in equation (18) the utility loss was not taxable. Otherwise, the logic leading to equation (27) is the same as the logic leading to equation (18).

It follows that firm $i$ 's profit is

$$
\pi_{i}(s)=2 \int_{0}^{1 / 2 N}\left(p_{i}(z)\left(1-\tau_{v}\right)-c-\tau_{s}-r . s\right) d s-f=\frac{r}{2 N^{2}}-f .
$$

This is precisely the same as the profit that firm $i$ earns when all tax rates are zero. It follows that when firms operate flexible technologies and are allowed to price discriminate, neither ad valorem nor specific taxes have any impact on product variety. All taxes are passed on in full to consumers. In other words, since the producer price at each consumer location is $\widetilde{p}_{i}(z)=c+\tau_{s}+r(1 / N-z)$ and $N$ is independent of $\tau_{v}$, there is no direct or indirect effect of ad valorem taxes on producer prices. 
What about the equilibrium number of basic products that will be established? By the same argument as in section 3 we know that with spatial contestability the equilibrium location configuration is such that all incumbents just break even. By contrast, with spatial non-contestability it must be that an entrant, who gains a market share $1 / 2 N$ and profits of one-quarter those of the incumbents, just fails to break even. It follows from (28) that the equilibrium number of product variants in these two cases is

$$
N_{d}^{S C}(r)=\sqrt{\frac{r}{2 f}} \quad N_{d}^{S N C}(r)=\sqrt{\frac{r}{8 f}}
$$

With spatial contestability there are too many basic products and with spatial noncontestability there are too few.

Much more fundamentally, an important implication of equations (28) and (29) is that government has lost the ability to use commodity taxes to move the industry to the optimal number of firms. Some other instrument will be needed but, as can be seen from (29) the options available to policy makers are limited. Equilibrium product variety is a function solely of customization costs, fixed costs and, implicitly, re-anchoring costs.

Table 2 summarizes our analytical results with respect to the equilibrium degree of product variety and the ad valorem tax rate needed to generate the socially optimal product variety for markets where firms may price discriminate. Only if the technology is designated and re-anchoring is costless is it optimal to levy an ad valorem tax to achieve desired product variety. If re-anchoring is prohibitively costly, then a subsidy is required. More striking is the result with flexible technology. Now tax policy is completely ineffective for achieving optimal product variety. Given the likely growth in importance of flexible technologies, this is a troubling result. 


\begin{tabular}{|c|c|c|c|}
\hline \multicolumn{4}{|c|}{ Table 2. Product Variety and Optimal Ad Valorem Tax Rates: } \\
Price Discrimination \\
\hline \multirow{2}{*}{ Technology } & Contestability & $\mathbf{N}^{*}-\mathbf{N}^{\mathbf{0}}$ & $\tau_{v}^{*}$ \\
\hline \multirow{2}{*}{ Designated } & SC & + & $50.0 \%$ \\
\cline { 2 - 4 } & SNC & - & $-100.0 \%$ \\
\hline \multirow{2}{*}{ Flexible } & SC & + & NA \\
\cline { 2 - 4 } & SNC & - & NA \\
\hline
\end{tabular}

\section{Policy Implications and Conclusions}

When regulations prohibiting price discrimination are rigidly enforced it is apparent that there is always excessive product variety in the absence of commodity taxes, no matter the ease with which firms can re-anchor their product specifications (the degree of spatial contestability) and whether or not firms adopt flexible technologies. The primary impact of such regulations is to protect firms against selective price cuts and so allow the firms to maintain higher prices than would be the case with price discrimination. This in turn leads to greater product variety than is socially desirable. In these circumstances, no matter the technological choices of firms, specific taxes can be used to generate tax revenues while ad valorem taxes can be used to affect market structure. All that changes with technology and re-anchoring costs are the magnitudes of the tax rates needed to generate the desired market structure and target tax revenues. When it is expensive for firms to change product design and image, prices are higher and product variety lower, as a result of which the authorities need lower unit taxes and specific taxes in order to attain desired revenue/market structure targets.

Deregulation that leaves firms free to price discriminate changes matters significantly. No matter whether firms adopt designated or flexible manufacturing techniques, it is apparent that with price discrimination the ease with which firms can reanchor the characteristics of their products "matters" for market structure and the design 
of commodity taxation policy. With designated or inflexible technologies it is still possible to assign instruments - unit taxes to revenue generation and ad valorem taxes to structural objectives - but it is no longer the case that the market will always support excessive product variety in the absence of taxes.

If firms employ designated technologies, spatial non-contestability in the presence of sophisticated pricing also differs from spatial contestability in allowing for the presence of rents in equilibrium. Ad valorem taxation will appropriate some of those rents to the extent that it reduces the number of firms in equilibrium. If price discrimination occurs, however, the optimal tax increases the number of firms and so increases aggregate rents in this market. This indicates the potential gains that arise from the ability to tax rents directly in non-contestable markets when price discrimination is allowed.

While we have dealt analytically with the two extremes - of zero and prohibitive re-anchoring costs - we can use Norman and Thisse (1999) to conclude more generally that the minimum sustainable degree of product variety is an inverse function of reanchoring costs. In other words, when re-anchoring is relatively inexpensive a positive ad valorem tax is necessary to achieve the optimal market structure. By contrast, when it is relatively expensive for firms to re-anchor their products they are able to make binding commitments to product specifications that deter entry sufficiently for a subsidy to be needed to attain the socially optimal market structure.

What we need are observable signals of the degree of spatial contestability. Some obvious candidates can be suggested. High initial entry costs, a high degree of product complexity and quality and high advertising expenditures - particularly those intended to build brand and corporate image - all point to a lack of spatial contestability. 
Matters are even worse with flexible manufacturing systems. It remains the case that the ease with which firms can re-anchor their basic products is important in determining whether or not product variety is excessive. However, now we find that commodity taxes can no longer be used to affect market structure. These taxes are passed on in full to consumers leaving no direct or indirect incidence on firms. If part of the motivation for deregulation was the belief that the tax system could be used to achieve optimal market structure, then policy analysts need to examine carefully the ease with which firms can customize or personalize their product offerings. Moreover, our analysis adds a further dimension to the current debate on taxation of Internet transactions. We noted in the introduction that modern developments in e-commerce allow firms to personalize or "version" their services in much the same manner that flexible manufacturing systems do. Our analysis then implies that any attempt to use commodity taxes to attain structural objectives in Internet-based markets is doomed to failure.

An alternative possibility can be suggested. The equilibrium that we have identified with price discrimination and spatial non-contestability is the minimum packing degree of product variety. We also indicated, however, that the market can support as an equilibrium any degree of product variety between this minimum packing and the maximum packing that zero re-anchoring cost generates. What this implies is that if policy can be formulated to encourage entry in emerging markets it may be possible to gain an outcome that is nearer to the social optimum even when commodity taxes are largely ineffective. 


\section{References}

Eaton, B. Curtis and Schmitt, Nicolas. "Flexible Manufacturing and Market Structure." American Economic Review, 1994, 84(4), pp. 875-88.

Eaton, B. Curtis and Wooders, Myrna Holtz. "Sophisticated Entry in a Model of Spatial Competition." RAND Journal of Economics, 1985, 16(2), pp. 282-97.

Kats, Amoz. "More on Hotelling's Stability in Competition." International Journal of Industrial Organization, 1995, 13(1), pp. 89-93.

Kay, John A. and Keen, Michael J. "How Should Commodities Be Taxed?" European Economic Review, 1983, 23(3), pp. 339-58.

Norman, George and Thisse, Jacques F. "Technology Choice and Market Structure: Strategic Aspects of Flexible Manufacturing." Journal of Industrial Economics, 1999, 47, pp. 345-72.

Norman, George and Thisse, Jacques-Francois. "Product Variety and Welfare under Tough and Soft Pricing Regimes." The Economic Journal, 1996, 106(434), pp. 76-91.

Novshek, William. "Equilibrium in Simple Spatial (or Differentiated Product) Models." Journal of Economic Theory, 1980, 22(2), pp. 313-26.

Salop, Steven C. "Monopolistic Competition with Outside Goods." Bell Journal of Economics, 1979, 10, pp. 141-56.

Stellin, Susan. "Internet Companies Learn How to Personalize Service," The New York Times. New York:, 2000.

U.S. Office of Technology Assessment. "Computerized Manufacturing Automation: Employment, Education and the Workplace," Washington, D.C.: U.S. Government Printing Office,, 1984. 